\title{
A EVOLUÇÃO DA UNIÃO ESTÁVEL NO BRASIL E A RECENTE EQUIPARAÇÃO COM O CASAMENTO PARA FINS SUCESSÓRIOS
}

\author{
Gabriela dos Santos Paixão ${ }^{1}$, Juliane Nagafugi de Souza Costa ${ }^{2}$ \\ ${ }^{1}$ Faculdade de Direito da Alta Paulista. \\ ${ }^{2}$ Universidade do Oeste Paulista - UNOESTE, curso de Direito, Presidente Prudente, SP. E-mail: \\ gabrielapaixao@hotmail.com
}

\begin{abstract}
RESUMO
O estudo em questão objetiva demonstrar o processo de evolução logrado pela união estável na sociedade brasileira ao longo da história e os avanços deflagrados após o seu reconhecimento constitucional como sendo uma entidade familiar idônea que goza da proteção do Estado. A presente pesquisa também será voltada à recente decisão do Supremo Tribunal Federal (STF) no julgamento dos Recursos Extraordinários 646.721 e 878.694, que decidiu pela equiparação sucessória da união estável em relação ao casamento civil. Na decisão, o STF declarou inconstitucional o artigo 1.790 do Código Civil de 2002, motivado pela vedação ao retrocesso e por julgar tal dispositivo como sendo violador de princípios.

Palavras-chave: União estável. Casamento. Supremo Tribunal Federal. Equiparação. Direito sucessório.

\section{THE EVOLUTION OF STABLE UNION IN BRAZIL AND THE RECENT EQUIPMENT WITH MARRIAGE FOR SUCCESSFUL PURPOSES}

\begin{abstract}
The study in question aims to demonstrate the process of evolution achieved by the stable union in Brazilian society throughout history and the progress made after its constitutional recognition as a suitable family entity that enjoys the protection of the State. The present research will also be directed to the recent decision of the Supreme Federal Court (STF) in the judgment of Extraordinary Appeals 646.721 and 878.694, which decided on the succession equation of the stable union in relation to civil marriage. In the decision, the STF declared unconstitutional article 1.790 of the Civil Code of 2002, motivated by the prohibition against retrocession and for judging such a device as violating principles.
\end{abstract}

Keywords: Stable union. Wedding. Federal Court of Justice. Equalization. Inheritance law.

\section{INTRODUÇÃO}

O Direito tem como escopo ser reflexo da sociedade na qual está inserido em determinado lugar e época, correspondendo às mudanças de comportamento, aos objetos de valoração e demais critérios axiológicos que regem a convivência social e a própria existência humana.

A família é considerada uma das mais remotas instituições que se faz presente no seio da sociedade. Conforme esta se modifica e adota outros valores, surgem novas formas de constituição de família, cuja aceitação, social e jurídica, vai sendo conquistada de forma gradativa.

No presente estudo, o objeto de análise é a entidade familiar denominada de união estável, que vem passando por significativos avanços. Como lecionado por Pablo Stolze Gagliano e Rodolfo Pamplona Filho (2012), quando se trata da evolução histórica da união estável no Brasil, é possível agrupá-la em momentos díspares que percorre desde a ampla rejeição, com a ausência de tutela jurídica, partindo para a tolerância e sua aceitação como fato social, até, por fim, atingir o reconhecimento e a valorização constitucional como sendo entidade familiar. 
A partir da promulgação da Constituição Federal de 1988 (CF/88) a união estável obteve proteção jurídica, sendo posteriormente regulamentada por leis infraconstitucionais e assumindo ainda relevância em face do Código Civil de 2002 (CC/02) e do Código de Processo Civil de 2015 (CPC/2015), como se verá ao longo da pesquisa.

Resta majoritário o entendimento de que inexiste hierarquia e predileção entre o tradicional modo de se constituir uma família, o casamento, e a união estável, sendo ambos entidades familiares juridicamente reconhecidas. Hodiernamente, a união estável caminha de forma paralela ao casamento, dispondo de uma proteção que visa de certa forma "equalizar" as entidades, equiparando significativamente os direitos dos companheiros aos direitos dos cônjuges.

Desse modo, o objetivo da presente pesquisa é tratar da união estável por meio da abordagem de seu conceito, elementos caracterizadores, regras de sucessão hereditária e regime de bens, demonstrando a evolução histórica pela qual a união estável vem passando, evidenciando, ainda, a recente decisão do Supremo Tribunal Federal (STF) no julgamento dos Recursos Extraordinários 646.721 e 878.694, que equiparou os direitos sucessórios na união estável em relação ao casamento civil, declarando inconstitucional o artigo 1.790 do Código Civil de 2002.

\section{METODOLOGIA}

A pesquisa se valeu do método dedutivo e dialético, desenvolvendo-se por meio de levantamento bibliográfico pautado em livros de doutrina, artigos científicos e demais documentos que se mostraram pertinentes e relacionados com o objeto de estudo, além de pesquisa jurisprudencial e legislativa acerca do tema, no intuito de cumprir com o objetivo proposto.

\section{DISCUSSÃO}

\section{DA UNIÃO ESTÁVEL: FUNDAMENTAÇÃO JURÍDICA, CONCEITO E ELEMENTOS CARACTERIZADORES}

À época em que a união estável não tinha aceitação como sendo modalidade idônea de família, recebia a denominação de "concubinato", expressão que, como expõem Pablo Stolze Gagliano e Rodolfo Pamplona Filho (2012), possui sentido fortemente pejorativo considerando que deriva da expressão latina concubere, significando "dividir o leito", refletindo a carga de preconceito da sociedade da época.

O marco inicial do reconhecimento da união estável como sendo entidade familiar encontra-se na Constituição Federal de 1988, esta que em seu texto declara expressamente no §3ㅇ do art. 226 que "para efeito da proteção do Estado, é reconhecida a união estável entre o homem e a mulher como entidade familiar, devendo a lei facilitar sua conversão em casamento".

Nesse diapasão é imperioso destacar que embora a CF/88 traga apenas as expressões "homem e mulher", por força da Resolução n. 175, de 14 de maio de 2013, do Conselho Nacional de Justiça (CNJ), os casais homoafetivos também estão amparados. A aludida Resolução determina a vedação às autoridades competentes de se recusarem a celebrar casamento civil ou de converter a união estável, entre pessoas do mesmo sexo, em casamento.

A união estável foi inicialmente disciplinada pela Lei n. 9.278 de 10 de maio de 1996 e Lei $n$. 8.971 de 29 de dezembro de 1994, que regulamentam o §3ㅇ do art. 226 da CF/88, acima transcrito. Após, pela CF/88, e atualmente a matéria vem prevista no Código Civil de 2002, ganhando espaço também no Código de Processo Civil de 2015, demonstrando o quanto essa forma de composição familiar vem se tornando reconhecida no âmago social e tutelada pelo ordenamento jurídico pátrio. 
A Lei n. 8.971/94 e a Lei n. 9.278/96 trouxeram as primeiras regulamentações da união estável. Em seguida o Código Civil de 2002, basicamente repetindo e incorporando o que as Leis supracitadas havia prescrito, dedicou o Título III, do Livro IV Do Direito de Família, exclusivamente ao tema dispondo sobre a união estável do art. 1.723 ao 1.727.

O novel Código de Processo Civil trouxe a influência da união estável também no âmbito processual, tratando, por exemplo, da inclusão do companheiro no rol de impedimentos do juiz no art. 144, incisos III, IV, e VIII do CPC, bem como da necessidade de constar na qualificação das partes a existência de união estável dentre os requisitos da petição inicial (CPC, art. 319, II).

Há ainda destaque no Novo Código quanto à outorga convivencial, conforme pode ser observado no §3ㅇ do art. 73 que trata da necessidade de haver o consentimento do companheiro para a propositura de ação que verse sobre direito real imobiliário. Dentre outros dispositivos esparsos no $\mathrm{CPC} / 2015$ que tocam na figura do companheiro.

Depois de traçados os fundamentos legais da união estável, cabe agora discorrer quanto ao seu conceito, este que é encontrado no art. 10 da Lei n. 9.278/96 e no art. 1.723 do CC/02. Tartuce (2017) ensina que tal conceito foi construído a partir da doutrina do professor Álvaro Villaça Azevedo, este que participou dos processos de elaboração da referida Lei e do aludido Código.

Da transcrição do art. 1.723 do CC/02 se verifica que "é reconhecida como entidade familiar a união estável entre o homem e a mulher, configurada na convivência pública, contínua e duradoura e estabelecida com o objetivo de constituição de família".

A união estável, portanto, é uma forma de composição de família tida constitucionalmente como entidade familiar que goza da proteção do Estado, união que prescinde de formalidade e solenidade, baseada, assim, na notoriedade, continuidade, estabilidade e no animus familiae. $\mathrm{E}$ alicerçada na "lealdade, respeito, mútua assistência, moral, afetiva, patrimonial, sexual, e espiritual bem como o dever de guarda, sustento e educação dos filhos", sendo estes os deveres dos companheiros (CC/02, art. 1.724).

Quanto à dispensa de formalidade para a caracterização da união estável, Carlos Roberto Gonçalves ensina que:

Uma das características da união estável é a ausência de formalismo para a sua constituição. Enquanto o casamento é precedido de um processo de habilitação, com publicação dos proclamas e de inúmeras outras formalidades, a união estável, ao contrário, independe de qualquer solenidade, bastando o fato da vida comum. (GONÇALVES, 2012, p. 587).

Neste mesmo prisma, do próprio conceito de união estável é possível extrair os seus elementos caracterizadores, ou seja, de acordo com Pablo Stolze Gagliano e Rodolfo Pamplona Filho (2012) a caracterização da união estável se dá por meio de elementos essenciais e elementos acidentais. Os essenciais são os que podem ser encontrados da sistematização do art. 1.723 do CC/02, já transcrito, a saber: a publicidade, a continuidade, a estabilidade, e objetivo de constituição de família.

De acordo com o doutrinador Flávio Tartuce (2017), o legislador ao tratar das expressões pública, contínua, duradoura e objetivo de constituição de família, deixou um sentido de modo aberto e genérico, necessitando da análise de cada caso concreto, considerando existir, com relação à constituição da união estável, uma verdadeira cláusula geral.

Já os elementos caracterizadores acidentais, ainda segundo a doutrina de Pablo Stolze Gagliano e Rodolfo Pamplona Filho (2012), são: o tempo, a prole e a coabitação. Estes que, ainda que não sejam essenciais para a configuração da união estável, colaboram facilitando e reforçando a sua existência. 


\section{DO REGIME PATRIMONIAL DA UNIÃO ESTÁVEL SEGUNDO O ATUAL CÓDIGO CIVIL: REGIME DE BENS E SUCESSÃO}

Dispõe o artigo 1.725 do Código Civil que à união estável se aplica, no que couber, as regras patrimoniais do regime da comunhão parcial de bens, salvo se existir contrato de convivência entre os companheiros.

O regime de comunhão parcial, para Sílvio Rodrigues:

É aquele em que, basicamente, se excluem da comunhão os bens que os cônjuges possuem ao casar ou que venham a adquirir por causa anterior e alheia ao casamento, como as doações e sucessões; e em que entram na comunhão os bens adquiridos posteriormente. Trata-se de um regime de separação quanto ao passado e de comunhão quanto ao futuro. (RODRIGUES, 2008, p. 178)

Desse modo, quanto ao regime de bens o Código Civil não faz distinção entre casamento e união estável, pois considera como supletivo para ambos o regime da comunhão parcial de bens, sendo que este pode ser modificado ou alterado através do pacto antenupcial, no casamento, e do contrato de convivência, na união estável.

Quanto à sucessão, as Leis n. 8.971/1994 e n. 9.278/1996, que regulamentaram o art. 226, $\S 3$ ? , da CF, reconhecendo a união estável como entidade familiar, asseguraram aos companheiros, dentre outros direitos, o de herdar. Inclusive, a primeira delas determinava a transmissão do patrimônio ao companheiro sobrevivente, e não aos colaterais, se inexistissem descendentes ou ascendentes.

Assim, o que se esperava da nova codificação cível era que ela viesse, finalmente, "igualar o tratamento entre cônjuges e companheiros, evitando qualquer alegação de tratamento discriminatório" (GAGLIANO; PAMPLONA FILHO, 2017, p. 239). Ambas as leis, porém, restaram tacitamente revogadas em face da inclusão da matéria no âmbito do Código Civil de 2002, o qual, segundo Sílvio Venosa (2017), conseguiu ser perfeitamente inadequado ao tratar do direito sucessório dos companheiros.

Dispõe, por um lado, o art. 1.790, ainda nas disposições gerais do Livro dos Direitos das Sucessões, que o companheiro participará da sucessão do outro somente quanto aos bens comuns e nas condições seguintes:

I - se concorrer com filhos comuns, terá direito a uma quota equivalente à que por lei for atribuída ao filho;

II - se concorrer com descendentes só do autor da herança, tocar-lhe-á a metade do que couber a cada um daqueles;

III - se concorrer com outros parentes sucessíveis, terá direito a um terço da herança;

IV - não havendo parentes sucessíveis, terá direito à totalidade da herança.

Já em seu art. 1.829, no Título da Sucessão Legítima, confere ao cônjuge supérstite a seguinte ordem sucessória:

I - aos descendentes, em concorrência com o cônjuge sobrevivente, salvo se casado este com o falecido no regime da comunhão universal, ou no da separação obrigatória de bens (art. 1.640, parágrafo único); ou se, no regime da comunhão parcial, o autor da herança não houver deixado bens particulares; 


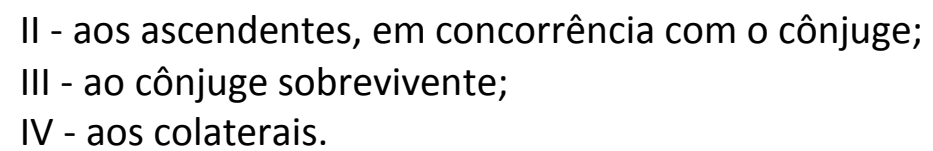

Ou seja, "enquanto as citadas leis que disciplinaram a união estável caminharam no sentido de igualar os direitos do companheiro aos do cônjuge, o Código Civil de 2002 tomou direção oposta", consoante Carlos Roberto Gonçalves (2016, p. 193). Pairando o regime de comunhão parcial de bens, os casados detêm direito sucessório com relação aos bens particulares do de cujos e aos companheiros limita-se àqueles adquiridos durante a união estável, sendo considerados, concomitantemente, meeiros e herdeiros, como aponta Tartuce (2017).

De acordo com a doutrina, "trata-se de tratamento demeritório da união estável em face do matrimônio, com uma disciplina que a desprestigia como forma de relação afetiva" (GAGLIANO; PAMPLONA FILHO, 2017, p. 242).

Com efeito, o art. 1.790 do vigente Código Civil confere ao companheiro viúvo um direito sucessório limitado aos bens adquiridos onerosamente no curso da união, além de colocá-lo em situação inferior aos colaterais do morto, um tio ou um primo, por exemplo.

Neste sentido, a concorrência sucessória se dará justamente nos bens a respeito dos quais o companheiro já é meeiro. Sendo assim, se o falecido não tiver adquirido nenhum bem na constância da união estável, ainda que tenha deixado valioso patrimônio formado anteriormente, o companheiro sobrevivente nada herdará, sejam quais forem os herdeiros eventualmente existentes.

Segundo Giselda Maria Fernandes Novaes Hironaka,

o art. 1.790 do CC restringiu a possibilidade de incidência do direito sucessório do companheiro à parcela patrimonial do monte partível que houvesse sido adquirido na constância da união estável, não se estendendo, portanto, àquela outra quota patrimonial relativa aos bens particulares do falecido, amealhados antes da evolução da vida em comum. A nova lei limitou e restringiu, assim, a incidência do direito a suceder do companheiro apenas àquela parcela de bens que houvessem sido adquiridos na constância da união estável a título oneroso. Que discriminação flagrante perpetuou o legislador, diante da idêntica hipótese, se a relação entre o falecido e o sobrevivente fosse uma relação de casamento, e não de união estável! (HIRONAKA, 2011, p. 420)

E sobre o mesmo dispositivo legal, Aldemiro Rezende Dantas Jr. coloca que:

Pensamos que o artigo 1.790, do Código Civil, deve ser destinado à lata do lixo, sendo declarado inconstitucional e, a partir daí, simplesmente ignorado, a não ser para fins de estudo histórico da evolução do direito. Tal artigo, num futuro não muito distante, poderá ser apontado como exemplo dos estertores de uma época em que o legislador discriminava a família que se formava a partir da união estável, tratando-a como se fosse família de segunda categoria. (DANTAS JR., 2005, p. 130)

Percebe-se, portanto, a explícita incongruência entre o art. 1.790 do Código Civil e a CF/88, que contempla diferentes formas de família, incluindo aquela formada pela união estável, sendo ilegítimo desequiparar, para fins sucessórios, os cônjuges e os companheiros. Nas palavras do Ministro do STF Luís Roberto Barroso "tal hierarquização entre entidades familiares é incompatível 
com a Constituição" (STF, Recurso Extraordinário 878.694/MG, Tribunal Pleno, Rel. Min. Luís Roberto Barroso, DJ 31.08.2015, com repercussão geral).

\section{DA EQUIPARAÇÃO SUCESSÓRIA DA UNIÃO ESTÁVEL AO CASAMENTO CIVIL: ANÁLISE DA DECISÃO DO STF}

Essa situação discrepante, entretanto, foi revista em maio do corrente ano (2017), quando, ao analisar dois Recursos Extraordinários (n. 646.721 e 878.694), ambos com repercussão geral reconhecida, os ministros do STF declararam inconstitucional o artigo 1.790 do Código Civil.

A equiparação das duas instituições começou a ser definida ainda em agosto de 2016, mas, na ocasião, pedido de vista do Ministro Dias Toffoli suspendeu a votação, retomada em março passado, quando houve novo pedido de vista, desta vez por parte do Ministro Marco Aurélio.

Ao fim, seguiu-se o voto do Ministro Relator Luís Roberto Barroso, segundo o qual existem diferenças entre casamento e união estável, não se podendo falar em equiparação absoluta, entretanto, não se pode admitir qualquer hierarquia entre as duas entidades familiares (TARTUCE, 2017). Ainda de acordo com o Ministro, quando o Código Civil desequiparou o casamento e as uniões estáveis, promoveu um retrocesso e uma hierarquização entre as famílias não admitida pela Constituição.

Nestes termos, a decisão do STF mostra que o art. 1.790/CC pode ser considerado inconstitucional por violar princípios constitucionais, como o da igualdade, dignidade da pessoa humana, ferindo também o princípio da proporcionalidade e da vedação ao retrocesso.

E nesse sentido, para fim de repercussão geral, foi aprovada a seguinte tese, válida para ambos os processos: "no sistema constitucional vigente é inconstitucional a diferenciação de regime sucessório entre cônjuges e companheiros devendo ser aplicado em ambos os casos o regime estabelecido no artigo 1.829 do Código Civil”.

\section{CONCLUSÃO}

A Lei n. 8.971/94, que regulamentou a união estável, estabeleceu a forma de suceder entre companheiros, a qual se equiparava à regra de sucessão entre cônjuges. Porém, o atual Código Civil passou a tratar de forma diferente e prejudicial os companheiros naquilo que se refere ao direito sucessório.

Essa nova regra vem contida no art. 1.790, CC, que foi alvo ao longo desse tempo de inúmeras alegações de inconstitucionalidade. O STF, que no início teve uma posição favorável à disposição do citado artigo, mudou seu direcionamento e em meados deste ano taxou de inconstitucional a mencionada regra, determinando que a sucessão entre companheiros deve seguir a mesma diretriz traçada para os cônjuges no artigo 1.829, CC.

É possível concluir, desse modo, que a união estável tem passado por um processo evolutivo significante nas esferas social e jurídica do país. Após ter sido reconhecida como entidade familiar pela Constituição Federal de 88, a matéria acabou evoluindo ainda mais, recebendo novos contornos pela sociedade e, consequentemente, pelo Direito, que deve acompanhar os valores cultivados pela coletividade.

Da análise da decisão do Supremo Tribunal Federal percebe-se que a Corte, na qualidade de Guardiã da Constituição, tem repudiado a ideia de haver hierarquização entre as entidades familiares por entender ser incompatível com os preceitos constitucionais.

Tendo em vista o seu status constitucional, a sua regulamentação pelo Código Civil e as recentes decisões judiciais, resta claro que a evolução da união estável no Brasil não se freará e passará a ocupar cada vez mais espaço nas pautas judiciais refletindo as constantes reivindicações por direitos. 


\section{REFERÊNCIAS}

BRASIL. Presidência da República. Constituição da República Federativa do Brasil. Disponível em: <http://www.planalto.gov.br/ccivil_03/constituicao/constituicaocompilado.htm>. Acesso em: 20 de jul. de 2017.

BRASIL. Presidência da República. Lei 10.406, de 10 de janeiro de 2002. Disponível em: <http://www.planalto.gov.br/ccivil_03/leis/2002/L10406.htm>. Acesso em: 20 de jul. de 2017.

BRASIL. Presidência da República. Lei 9.278, de 10 de maio de 1996. Disponível em: <http://www.planalto.gov.br/ccivil_03/leis/L9278.htm>. Acesso em: 20 de jul. de 2017.

BRASIL. Presidência da República. Lei 13.105 de 16 de março de 2015. Disponível em: <http://www.planalto.gov.br/ccivil_03/_ato2015-2018/2015/lei/l13105.htm>. Acesso em: 21 de jul. de 2017.

DANTAS JR., Aldemiro Rezende. Concorrência sucessória do companheiro sobrevivo. Revista Brasileira de Direito de Família, Porto Alegre: Síntese, IBDFAM, ano VII, n. 29, p. 128-143, abr./maio, 2005.

GAGLIANO, Pablo Stolze; PAMPLONA FILHO, Rodolfo. Novo Curso de Direito Civil, Volume 6: direito de família - As famílias em perspectiva constitucional. 2. ed. São Paulo: Saraiva, 2012.

GAGLIANO, Pablo Stolze; PAMPLONA FILHO, Rodolfo. Novo Curso de Direito Civil, Volume 6: direito das sucessões. 4. ed. São Paulo: Saraiva, 2017.

GONÇALVES, Carlos Roberto. Direito Civil Brasileiro, volume 6: direito de família. 9. ed. São Paulo: Saraiva, 2012.

GONÇALVES, Carlos Roberto. Direito Civil Brasileiro, volume 7: direito das sucessões. 9. ed. São Paulo: Saraiva, 2016.

HIRONAKA, Giselda Maria Fernandes Novaes. Morrer e suceder. São Paulo: RT, 2011.

OLIVEIRA, Euclides Benedito de. Direito de herança: a nova ordem da sucessão. São Paulo: Saraiva, 2005.

RODRIGUES, Sílvio. Direito civil: direito de família. 28. ed. São Paulo: Saraiva, 2008.

SUPREMO TRIBUNAL FEDERAL. Julgamento afasta diferença entre cônjuge e companheiro para fim sucessório. 2017.2 Disponível em: <http://www.stf.jus.br/portal/cms/verNoticiaDetalhe.asp?idConteudo=342982> Acesso em: 16 jul. de 2017.

TARTUCE, Flávio. Manual de Direito Civil: volume único. 7. ed. Rio de Janeiro: Forense; São Paulo: Método, 2017. 